\title{
The Lapita-associated Human Material from Lakeba, Fiji
}

\author{
Philip Houghton \\ Department of Anatomy, University of Otago \\ P.O. Box 913, Dunedin, New Zealand
}

\begin{abstract}
The remains of an individual interred about the middle of the first millenium BC, in association with Lapita ceramics, on the island of Lakeba in the Lau group of Fiji, have been examined. The long bones were robust and showed marked bowing and other evidence of considerable muscularity. The femur had an oval fovea and marked platymeria (index 71). Stature was estimated at $1,715 \mathrm{~mm}$. The incomplete jaw was of 'rocker' form on one side and showed a very slight antegonial notch on the other. The morphology of this individual is fully compatible with the known Polynesian skeletal phenotype.
\end{abstract}

Houghton, P., 1989. The Lapita-associated human material from Lakeba, Fiji. Records of the Australian Museum 41(3): 327-329.

Human remains associated with typical Lapita ceramics have been excavated on the island of Lakeba in the Lau group of Fiji (Best, 1984). The material was greatly fragmented, but a useful assessment of phenotypic affinities was possible for one individual (from Site 196: trench 28). Carbon-14 dates for the initial occupation of the site early in the first millenium BC indicate interment towards the middle of that interval (Best, 1984: 100-105).

\section{Material}

The remains were of an adult male, probably in the fourth decade of life (30 to 40 years). The long bones were robust (though a defined robusticity index was not obtainable) and with physiologically bowed shafts to accommodate a considerable musculature. The maximum length of the intact right radius was $245 \mathrm{~mm}$, and of the right ulna $266 \mathrm{~mm}$. Derived stature estimates using different equations are given in Table 1 . The Polynesian equations of Houghton et al. (1975) gave the mid-estimates and also the least range; a stature of $1,715 \mathrm{~mm}$ is suggested. The upper femoral shafts were markedly flattened with a platymeric index of 71, rather greater than that found in the prehistoric Maori (Schofield, 1959) but similar to prehistoric Hawaii (Snow, 1974). The femoral heads showed distinct oval foveae (Fig.2). The forearm bones showed the marked bowing characteristic of Polynesians and the humeri showed prominent deltoid tuberosities. The spine was represented by several vertebrae from neck to lumbar region. It showed very little degeneration compared with prehistoric New Zealanders of the same age, where lumbar and cervical degeneration are often very advanced by the mid-30s. Clavicles show first-rib grooves, right more than left, suggesting regular canoe paddling. The right upper limb bones are slightly more robust than the left and this individual was thus presumably right-handed.

The cranial fragments offered little information, but the mandibular body and about half of each ramus were present. This bone was not particularly robust, though function would have been influenced by extensive dental caries in both jaws. The mandible verged on the rocker form, the right side displaying no antegonial notch and 